\title{
Microbial Remediation
}

\author{
Maulin P Shah* \\ Industrial Waste Water Research Lab, Division of Applied \& Environmental Microbiology, Enviro Technology, India
}

Submission: August 05, 2018; Published: August 09, 2018

*Corresponding author: Maulin P Shah, Industrial Waste Water Research Lab, Division of Applied \& Environmental Microbiology, Enviro

Technology, India, Email: shahmp@beil.co.in

\section{Editorial}

"Remediation" is problem solving and "biological remediation" refers to the use of biological organisms to solve environmental problems, such as contaminated soil or groundwater. Bioremediation means the use of a biological agent to suppress or clear contamination. This is different from remedial measures were contaminated soil or water is removed for chemical or decontamination or incineration or burial in a landfill. Microbes are often used to correct environmental problems in soil, water and sediment. Plants were also used to support bioremediation processes. This is called phytoremediation. For some inorganic materials such as metals, biological processes have been used to reduce radioactivity and remove organic contaminants. With metallic contamination, the usual task is to accumulate metal in the residual plant parts, which must be disposed of before or after incineration in a hazardous waste landfill site to reduce the ash. The two exceptions are mercury and selenium, which can be released as volatile elements directly from plants to the atmosphere. The concept and practice of using plants and micro-organisms to remediate contaminated soil has almost developed over the past 30 years. Key players in bioremediation are bacterial-microscopic organisms that live virtually everywhere. Micro-organisms are ideally suited to the role of contaminating contaminants because they have enzymes that allow them to use contaminants as food and because they are so small they are able to easily contact pollutants.

In situ bioremediation is considered to be an extension of the goal that the microorganisms used in nature for billions of years: the collapse of complex waste of people, animals and plants so that life can continue from one generation to the next. Without the activity of micro-organisms, the country would literally be buried in the waste, and the nutrients needed to continue life would be closed in detritus. Whether microorganisms are successful in destroying artificial contaminants in the underground depends on three factors: the type of organism, the type of contaminant, and the geological and chemical conditions in the contaminated site. It assesses how microorganisms destroy contaminants and what kinds of organisms play a role in in situ bioremediation. It then evaluates which contaminants are most susceptible to bioremediation in the subsurface layer and describes the types of sites where bio-mediation is most likely to succeed. In an unpolluted environment, bacteria, fungi, counterparts and other microorganisms are constantly decomposed into organic matter. What would happen if this environment polluted organic pollutants such as oil? Some of the micro-organisms would die, while others capable of eating organic pollution would survive.

Bioremediation works by providing fertilizers, oxygen and other conditions that promote rapid growth of these pollutants. These organisms could then decompose an organic pollutant corresponding to a faster rate. In fact, bioremediation is often used to clean up oil spills. Bioremediation of the contaminated site typically works in one of two ways. In the case described above, it has been found that ways to increase the growth of any pollutant microbes could already be in the contaminated site. In the second, less common case, specialized microbes are added which degrade the contaminants. The goal is to stimulate bioremediation microorganisms with nutrients and other chemicals that allow them to destroy contaminants. The bioremediation systems that are used today rely on microorganisms from contaminated sites and encourage them to work by enabling them to provide optimal amounts of nutrients and other chemicals necessary for their metabolism. The current bioremediation systems are therefore limited abilities of indigenous microbes. However, scientists are currently studying ways to extend sites contaminated with unsaturated microbes - including genetically modified micro-organisms specially adapted to the degradation of contaminants that relate to specific locations. It is possible that this process, known as bioaugmentation could expand the range of possibilities for future bioremediation systems. Regardless of whether the microbes are natural or newly introduced in place, understanding how destructive contaminants is essential to understanding bioremediation. Types of microbiology processes, which are used for cleaning, determine which nutritional supplements provide a bioremediation system. In addition, microbial process byproducts can provide bioremediation indicators are successful. However, bioremediation provides a technique to clean up 
pollution by increasing the same biodegradation processes that occur in nature. Depending on the site and its contaminants, bioremediation can be safer and cheaper than alternative solutions such as incineration or land filling of contaminated materials. It also has the advantage that the pollution is in place so that a large amount of soil, sediments or water need not be cleaned or exhausted from the ground for treatment.

Part of the effort to conserve scientists' resources focuses on the effective use of bioremediation for contaminated waste. Contaminated waste comes from two different reasons - Natural and artificially created. There are many different natural processes of contamination that occur as material or substance decomposes. As it moves in its stages of decomposition, different levels of toxins may be present. This person is able to create a huge amount of contamination is well known. Yet their removal with unnatural substances has proven to be a solution. If waste is biologically mediated, it can be recycled or at least stored so as not to damage the environment. Specialists are constantly looking for ways of natural bankruptcy and remediation to understand how they can be manipulated to help handle artificially created waste. This will help prevent further contamination from the waste or the products that treat it. Bioremediation is one of the most cost-effective and safe solutions we now have to deal with contaminated waste. 